\title{
Fusões e Aquisições das Unidades Produtivas e da Agroindústria de Cana-de-açúcar no Brasil e nas Distribuidoras de Álcool Hidratado Etílico
}

\author{
Paulo Henrique de Lima Siqueira ${ }^{1}$ \\ Luiz Gonzaga de Castro Junior ${ }^{2}$
}

\begin{abstract}
Resumo: As fusões e aquisições no Brasil tiveram um grande salto na década de 90 e o setor produtivo da agroindústria da cana-de-açúcar foi um dos destaques. Os efeitos causados no mercado por essas transações podem ser positivos ou negativos, tanto para as empresas diretamente envolvidas como para a sociedade como um todo. Esta pesquisa foi realizada com o objetivo de analisar a concentração de mercado das unidades produtivas e da agroindústria de cana-de-açúcar no Brasil e dos distribuidores de álcool hidratado etílico. Foram utilizados como métodos as taxas de concentração $\mathrm{C}_{4}, \mathrm{C}_{8}, \mathrm{C}_{20} \mathrm{e}$ o Índice de Hirschman-Herfindahl (HHI), além do levantamento de outros estudos e informações em periódicos. As unidades produtivas vêm diminuindo sua concentração, principalmente em função de as empresas de pequeno e médio porte terem aumentado sua escala de produção, sendo, portanto, ainda muito pulverizadas. A agroindústria também se mostrou muito pulverizada, apesar do intenso processo de fusão e aquisição ocorrido entre essas empresas nos últimos anos. Por outro lado, os distribuidores de álcool hidratado etílico vêm apresentando significativa concentração no mercado. Com tudo isso, pode-se dizer que o processo de fusão e aquisição tende a se intensificar entre as unidades produtivas e a agroindústria processadora de cana-de-açúcar no mercado nacional.
\end{abstract}

Palavras-chaves: Cana-de-açúcar, cadeia agroindustrial, fusões e aquisições.

\footnotetext{
${ }^{1}$ Doutorando da Universidade Federal de Lavras. E-mail: p33108@hotmail.com

${ }^{2}$ Professor da Universidade Federal de Lavras. E-mail: lgcastro@ufla.br
} 
710 - Fusões e Aquisições das Unidades Produtivas e da Agroindústria de Cana-de-açúcar no Brasil e nas Distribuidoras de Álcool Hidratado Etílico

Abstract: Mergers and acquisitions in Brazil had improved in the 90's, and the productive section of the sugarcane agroindustry was one of the highlights. Effects caused by these transactions in the market can be positive or negative for both companies directly involved and the society. The objective of this research is to analyze the market concentration of producing units, the agroindustry of sugarcane and the ethyl hydrous ethanol distributors in Brazil. We have used as methods the concentration rates $\mathrm{C}_{4}, \mathrm{C}_{8}, \mathrm{C}_{20}$, the Hirschman-Herfindahl Index (HHI), and researches in another studies, journals and newspapers. The productive units have been decreasing their concentration, caused mainly by the increased production scale of the small and medium companies, resulting, therefore, in still very distributive productive units. The agroindustry was also very distributive, in spite of the intense merger and acquisition process that happened among those companies over the last years. On the other hand, distributors of ethyl hydrous ethanol have improved their concentrations in the market. With all this, it can be said that the merger and acquisition process might step up among producing units and the agroindustry which process sugarcane in the domestic market.

Key-words: Sugarcane, agroindustry, mergers and acquisitions.

Classificação JEL: L 16; L 66.

\section{Introdução}

No final dos anos 1980, quando o processo de fusões e aquisições em países desenvolvidos se estabilizou, os investimentos diretos nesses países reduziram-se e se deslocaram para os países em desenvolvimento. A partir desse período, governantes brasileiros empreenderam uma política de maior abertura econômica ao exterior, incentivando a entrada de capital externo, em que a maior parte foi caracterizada como investimento direto, resultado de privatizações, fusões e aquisições de empresas nacionais (NASCIMENTO, 1999).

De acordo com o levantamento da KPMG Corporate Finance, na década de 90, a economia brasileira foi caracterizada por apresentar crescimento acumulado de $134 \%$ no número de transações de fusões e aquisições. Essa década pode ser dividida em três períodos: o primeiro, que vai até 1993, foi caracterizado pela abertura da economia brasileira, com pulverização, privatização, concentração e verticalização do mercado. Nesse período, foram 
registradas grandes fusões e aquisições em setores considerados básicos, como produtos químicos e petroquímicos, metalurgia e siderurgia. O segundo, que foi de 1994 até 1997, caracterizou-se pela emancipação do Plano Real e a presença expressiva de transações no setor financeiro, eletrônico e de autopeças. Globalização, concentração e socorro a bancos em dificuldades foram a tônica desse período. Finalmente, no terceiro período, de 1998 a 2000, as transações foram lideradas por setores mais avançados, como telecomunicações e tecnologia de informação. Esse período foi caracterizado por globalização, privatização, novas tecnologias e internet.

O setor de alimentos comportou grande gama de fusões e aquisições nesse período. Grandes organizações, como Cargill, Arisco, Sadia e Parmalat, realizaram grandes aquisições de pequenas e médias empresas durante a década de 90. No total do estudo, o setor de alimentos ficou em primeiro lugar no ranking, com 269 operações, 57\% delas com participação do capital estrangeiro.

Esse processo continuou se intensificando nos últimos anos. Entre os anos de 2000 e 2008, ocorreram 3.647 fusões e aquisições, sendo 354 no setor de alimentos, bebidas e fumo.

Neste contexto, o setor de açúcar e álcool vem passando por intenso período de concentração e centralização de capitais. A profissionalização do setor, com a substituição gradativa da administração familiar por executivos de mercado, e a maior capitalização das usinas, diante da recuperação do mercado internacional a partir de 2000 , foram as peças chaves para a aceleração do processo de fusão e aquisição no setor (AGRIANUAL, 2002).

A reestruturação da agroindústria canavieira está inserida em um processo mais amplo de intenso movimento de concentração e centralização de capitais na agroindústria nacional, com o aumento das falências, fusões e aquisições, e com a instalação de novas usinas pertencentes a grupos econômicos tradicionais. Dois fenômenos vêm sendo observados: a concentração e a centralização de capitais e a transferência de capitais do setor de uma região para outra, com instalação de novas unidades produtivas, principalmente na região CentroOeste e em Minas Gerais (EID; PINTO, [199_]).

O processo de fusões e aquisições nesse setor vem se caracterizando pelo aumento da presença de grandes grupos locais, como Grupo José Pessoa, Cosan e Carlos Lyra, e pela entrada de grandes grupos internacionais no mercado local, como Louis Dreyfus Commodities (LDC) e Tereos. A concentração das compras tem ocorrido na região Sudeste, principalmente devido aos custos mais baixos de produção. 
712 - Fusões e Aquisições das Unidades Produtivas e da Agroindústria de Cana-de-açúcar no Brasil e nas Distribuidoras de Álcool Hidratado Etílico

Diante dessas transformações no setor, questiona-se: esse processo tem efetivamente se intensificado? Há possibilidade de que ele se intensifique no futuro? Como tem se comportado o processo de concentração entre alguns elementos a jusante da cadeia agroindustrial da cana-de-açúcar?

Esse estudo foi realizado com o objetivo de analisar a concentração de mercado das unidades produtoras e da agroindústria de cana-de-açúcar no Brasil e dos distribuidores de álcool. Na próxima unidade discute-se a evolução da agroindústria sucroalcooleira nos últimos anos e, em seguida, abordam-se as implicações presentes nas fusões e aquisições e, depois, discute-se a metodologia aplicada no estudo. Finalmente, apresentam-se a análise e a conclusão do estudo.

\section{A evolução da agroindústria sucroalcooleira}

A agroindústria sucroalcooleira, assim como outros setores da economia brasileira, recebeu fortes incentivos governamentais por várias décadas, principalmente a partir da Segunda Guerra Mundial, com a Política de Substituição das Importações. A política de subvenção do governo federal no setor iniciou-se basicamente com a implantação, em 1933, do IAA ${ }^{3}$, que visava o fomento e o controle da produção de açúcar e álcool em todo o território nacional. Em 1975, com as crises do petróleo na década de 70 e da queda de preço do açúcar, o governo federal instituiu o Proálcool ${ }^{4}$, criado para atender aos interesses dos usineiros, como um mecanismo de superar a crise da economia açucareira; do Estado, para melhorar os indicadores econômicos; do setor de máquinas e equipamentos, dando continuidade ao crescimento que havia sido iniciado no final dos anos 60 e da indústria automobilística, com o carro movido a álcool como alternativa de expansão do transporte rodoviário (COELHO, 1998; LAGES, 1993; SHIKIDA; BACHA, 1999).

O Proálcool passou por três fases evolutivas: de expansão moderada, entre 1975 e 1979; de expansão acelerada, entre 1980 e 1985, e de desaceleração e crise, entre 1986 e 1995, devido à queda do preço internacional do petróleo e à crise das contas governamentais (SHIKIDA; BACHA, 1998).

Com a abertura comercial brasileira verificada no início da década de 90 , principalmente com o estabelecimento do Plano Real, em 1994, a agroindústria

\footnotetext{
3 Instituto do Açúcar e do Álcool

4 Programa Nacional do Álcool - Programa do governo que visava incentivar a produção de álcool como combustível.
} 
sucroalcooleira passou por profundas transformações, com o Estado diminuindo sua atuação subvencionista.

Esse processo de desregulamentação do Estado teve início em 1988, com o fim das quotas e do impedimento das exportações de São Paulo (VEGRO et al., 2003) e, em 1989, o IAA foi extinto.

Esse processo continuava nos anos seguintes, com a liberação gradativa dos preços dos produtos. O primeiro a ser liberado foi o preço do açúcar (1990), seguido pelo do álcool anidro (1997), pelo da cana-de-açúcar (1998) e, depois, do álcool hidratado (1999). Consequentemente, surgiu um novo processo de delineamento das atividades da agroindústria sucroalcooleira e o planejamento e as atividades de produção e comercialização deixaram de ser orientados pelo governo e passaram a fazer parte da administração privada (MARJOTTAMAISTRO, 2002).

Para muitos usineiros, o governo se afastou num momento de superoferta dos produtos no mercado, resultando em queda expressiva dos preços, abaixo, inclusive, dos custos de produção, provocando a falência de muitas usinas e exigindo uma nova estrutura de coordenação dentro do sistema agroindustrial sucroalcooleiro (MORAES; SILVEIRA, 2003).

Para um setor como a agroindústria sucroalcooleira, no qual a presença do Estado e seu papel de mediação sempre foram fundamentais para a elaboração de um projeto comum, o desafio que se colocava na década de 90 era de como o setor poderia encontrar novas formas de articulação entre os seus diversos segmentos. A cadeia agroindustrial da cana-de-açúcar nesse período teve dificuldades de se emancipar como bloco de interesses constituídos, surgindo uma série de interesses fragmentados e refletindo um enfoque conjunto de alternativas estratégicas que se apresentaram para as diferentes empresas atuantes no setor (BELIK et. al., 1998). Além disso, o setor sofreu críticas quanto aos impactos ambientais causados por suas atividades produtivas e quanto às condições de trabalho precárias e escravistas adotadas por algumas empresas sucroalcooleiras (MUNDO NETO, 2009).

Muitas das empresas produtoras de açúcar e álcool não se acostumaram com a diminuição do protecionismo estatal, ampliando os problemas de endividamento, ocasionando a diminuição do número de usinas e destilarias, impulsionadas pelas mudanças patrimoniais (SICSÚ; SILVA, 2001). Apesar dessas dificuldades, as empresas que sobreviveram à desativação do Proálcool modernizaram-se, passando de um setor totalmente atrelado ao governo para outro totalmente desregulamentado, inserindo-se numa economia de livre mercado (Sindaçúcar-MG, 2003). 
714 - Fusões e Aquisições das Unidades Produtivas e da Agroindústria de Cana-de-açúcar no Brasil e nas Distribuidoras de Álcool Hidratado Etílico

Além disso, com a emancipação dos carros flex fuel, que possibilitam a utilização tanto do álcool como da gasolina no mesmo veículo, os usineiros tiveram maior segurança quanto às possibilidades de mercado, visto que, na terceira fase do Proálcool, muitos consumidores deixaram de comprar carros a álcool, em função da queda do preço do petróleo.

Em 1997, surgiu a Unica (União da Indústria de Cana-de-Açúcar), que buscava conciliar os interesses conflitantes entre organizações de representação numa nova forma de empresariado nacional, mas incorporando as formas anteriores de representação da tradição corporativa. Isso porque, tanto a presidência do Sindicato da Indústria do Açúcar no Estado de São Paulo (Siaesp), como a do Sindicato da Indústria da Fabricação do Álcool no Estado de São Paulo (Sifaesp) são exercidas pelo presidente da Unica (MUNDO NETO, 2009).

A tendência que se visualiza no setor é a de novas estratégias individuais, baseadas na diferenciação do produto, principalmente pela qualidade, diversificação produtiva, produtividade, especialização, disponibilidade de entrega e abastecimento, buscando-se maior competitividade (MARJOTTAMAISTRO; BURNQUIST, 1998; BELIK et. al., 1998).

Para alavancar essa tendência, a agroindústria do açúcar e do álcool vem passando por intenso processo de fusões e aquisições, com a participação de grandes grupos nacionais e estrangeiros.

\section{As fusões e aquisições}

Uma firma pode incrementar seu tamanho no mercado por meio de investimentos na construção de novas fábricas, ou das fusões e aquisições, em que os ativos de duas ou mais firmas são combinados para gerar uma nova empresa (CARLTON; PERLOFF, 1999).

Segundo Oliveira (2007), fusão seria a combinação de dois ou mais negócios, em que há troca de ações ou dinheiro para compartilhar direitos e obrigações, ou as empresas são dissolvidas e os direitos e obrigações são combinados. Aquisição significa que uma empresa adquire o controle acionário total ou parcial de outra empresa.

As fusões e aquisições fazem parte das estratégias de crescimento das empresas. Elas podem ser de três tipos principais: horizontal, vertical e diversificação. Na horizontal, uma firma se agrega à outra, que desenvolve a 
mesma atividade; na vertical, ela se une à outra, a montante ${ }^{5}$ ou a jusante ${ }^{6}$ de sua cadeia de produção e, finalmente, numa diversificação, uma firma se une às outras firmas de diferentes atividades econômicas. A diversificação é concêntrica quando a empresa comprada tem produção, tecnologia, produtos, canais de distribuição e/ou mercados similares aos da empresa compradora. Já a diversificação não relacionada ou conglomerada é quando a empresa adquirida possui uma linha de negócios completamente diferente (CERTO et. al, 2005; SHEPHERD, 1999).

Fusões e aquisições podem ser desejáveis, tanto pelas firmas, quando incrementam sua lucratividade, quanto pela sociedade, quando aumentam a eficiência e, consequentemente, o bem-estar social. Infelizmente, para as firmas, nem todas as fusões e aquisições resultam em maior lucro. Além disso, ainda que elas sejam lucrativas, podem ser prejudicial para a sociedade por meio da redução da eficiência (CARLTON; PERLOFF, 1999).

Segundo Shepherd (1999), o principal motivo para as fusões e aquisições é, sem dúvida, o incremento da lucratividade que elas podem proporcionar, principalmente pelo aumento do poder do mercado, da economia tecnológica e da economia pecuniária.

Fusão, ou aquisição horizontal, aumenta o poder de mercado da firma, pois ela elimina seus principais concorrentes, gerando grande ou pequeno efeito, dependendo da participação de mercado das firmas e de outras condições do mercado. Quanto às fusões e às aquisições verticais, existem muitas discussões que são a favor e contrárias à sua influência sobre o poder de mercado. A fusão conglomerada, por juntar diversas atividades diferentes, dificilmente muda a estrutura de mercado diretamente, o que não incrementa o poder de mercado.

Várias formas de economia tecnológica podem ser ativadas por meio das fusões e aquisições. A primeira é a economia de escala, em que a fusão horizontal pode proporcionar maior produção com custos médios minimizados. Uma segunda seria a economia vertical, em que a fusão e aquisição de firmas de níveis diferentes podem diminuir os custos de transação, e a terceira seria a economia de diversificação, que diminui o risco do negócio, além da sinergia oriunda da interação de diferentes tecnologias e gerenciamentos entre as conglomeradas.

A economia pecuniária se mostra, principalmente, por meio das vantagens promocionais, com a diluição dos custos de propaganda, força de vendas e outros serviços promocionais, entre os vários negócios das empresas.

\footnotetext{
5 A montante refere-se às empresas que são fornecedoras de uma determinada empresa.

${ }^{6}$ A jusante refere-se às empresas que são compradoras de uma determinada empresa.
} 
716 - Fusões e Aquisições das Unidades Produtivas e da Agroindústria de Cana-de-açúcar no Brasil e nas Distribuidoras de Álcool Hidratado Etílico

Além desses aspectos salientados por Shepherd (1999), a maior parte das inovações tecnológicas que diversificam atividades, produtos e processos das empresas, e que vêm proporcionando o desenvolvimento econômico e social dos últimos anos, surge dos laboratórios das grandes empresas. Nesse contexto, a competitividade delas se traduz na capacidade de criar inovações tecnológicas adquiridas ao longo do tempo por meio dos seus investimentos em pesquisa e, devido aos seus altos custos e à lenta maturação de seus resultados, constituem um privilégio das grandes empresas (SZMRECSÁNYI, 2001). Assim, as firmas precisam crescer e as fusões e aquisições exercem papel importante.

Quando os custos dos fatores de produção mudam, o tamanho ótimo da empresa também muda. No final do século XIX, os custos de transporte e de comunicação tiveram queda acentuada, com o advento das estradas de ferro, do telégrafo e do telefone. Além disso, houve desenvolvimento do mercado financeiro, com o surgimento, por exemplo, do mercado de ações, que diminuiu os custos de captação de recursos. Com isso, as empresas americanas foram incentivadas a incrementar o tamanho, buscando escala ótima de produção e utilizando as fusões e aquisições (CARLTON; PERLOFF, 1999).

Apesar dessas questões positivas, existe uma rica literatura de pesquisa sobre os malefícios e as falhas de muitas fusões e aquisições. Geralmente, elas ocorreram porque as fusões e aquisições foram debilmente planejadas, realizadas pelo simples desejo da liderança e de aumentar o tamanho das instalações, baseando-se na falsa esperança de alcançar sinergia ou, ainda, porque procuravam agregar corporações com estilos administrativos diferenciados (SHEPHERD, 1999).

Fahey e Randall (1999) afirmam que as empresas podem objetivar fazer fusões e aquisições para aproveitar excepcional oportunidade de mercado, como crescimento extremamente elevado; compensar as baixas taxas de crescimento do mercado atual; criar um fluxo de lucros mais estável; reinvestir excesso de caixa em novas empresas para evitar a dupla tributação de dividendos e explorar as sinergias positivas ${ }^{7}$ entre as empresas ou entre uma empresa e a matriz corporativa. Destes, o objetivo mais racional seria o último, tomando cuidado, entretanto, de não deixar de considerar a sinergias negativas ${ }^{8}$, exagerar na avaliação da sinergia positiva e menosprezar os desafios gerenciais na realização das sinergias potenciais.

\footnotetext{
7 Sinergia positiva: vantagens resultantes da fusão e aquisição, como diminuição dos custos pela diluição dos gastos entre as empresas, vantagens utilizando o mesmo canal de distribuição, ampliação do mercado etc.

8 Sinergia negativa: as desvantagens resultantes da fusão e aquisição, como diferenças culturais, elevado ágio pelo controle, gastos com honorários de bancos de investimentos, advogados e contadores e a alocação de despesas corporativas à unidade adquirida.
} 
Segundo Shepherd (1999), fusões e aquisições podem acontecer amigavelmente ou ser o resultado de uma forte hostilidade entre as empresas.

Do ponto de vista de perda para a sociedade, o tamanho das firmas após a fusão ou aquisição pode ser muito elevado, fazendo com que elas tenham grande parcela de mercado, o que proporciona forte poder de monopólio, ou seja, essas firmas passam a produzir menos, a preços bem acima do custo de produção. Os órgãos governamentais procuram regulamentar esse processo, evitando a perda para a sociedade, mas a presença de lobistas no governo pode ser um mecanismo que neutralize esse processo (CARLTON; PERLOFF, 1999).

Pesquisadores da Escola de Chicago desenvolveram uma nova hipótese: qualquer queixa por parte de alguma firma rival sobre uma fusão ou aquisição mostra simplesmente que essa rival é ineficiente. Portanto, qualquer pressão sobre essa rival é positiva, porque ela é forçada a melhorar a performance. Entretanto, essa argumentação da Escola de Chicago depende inteiramente de uma suposição: a de que não há imperfeições no mercado. Caso haja alguma imperfeição, a fusão pode apresentar impactos anticompetitivos e as reivindicações das rivais podem ser válidas (SHEPHERD 1999).

Portanto, ao se estudar os impactos das transações de fusões e aquisições sobre o mercado, deve-se levar em consideração as mudanças na concentração do mercado exercida pelas grandes firmas nas barreiras de entrada e na capacidade de manutenção das outras empresas existentes no mercado.

\section{Metodologia}

Segundo Shepherd (1999), os principais elementos da estrutura de mercado são participação de mercado, concentração e condições de entrada. A parcela de mercado é o indicador mais simples e importante do grau de poder do monopólio. Grande parcela de mercado quase sempre é acompanhada por elevado grau de poder de monopólio. O grau de concentração de mercado é estimado diretamente pela combinação das parcelas de mercado das grandes firmas, geralmente das quatro maiores. A concentração é importante porque ajuda a analisar o grau de oligopólio. Os oligopolistas podem agir de três formas distintas: coordenar fortemente suas ações, de tal maneira que as aproxime de um monopolista genuíno, competir fortemente no mercado ou, ainda, se manter num meio termo entre esses dois extremos.

As condições de entrada no mercado se traduzem na barreira de entrada, que é uma vantagem que os vendedores estabelecidos em uma indústria têm sobre os vendedores entrantes potenciais, que reflete na capacidade que os 
718 - Fusões e Aquisições das Unidades Produtivas e da Agroindústria de Cana-de-açúcar no Brasil e nas Distribuidoras de Álcool Hidratado Etílico

primeiros têm de persistentemente poder aumentar seus preços acima do nível competitivo, sem atrair novas firmas para entrar na indústria (BAIN, 1956).

Elas podem ser classificadas como exógenas, ou seja, quando são inerentes e fora de controle das firmas, como economia de escala, integração vertical e elevado risco e incerteza de entrada. Também existem as barreiras endógenas, que são causadas pelas estratégias das empresas, como investimento em propaganda, segmentação de mercado e uso de patentes (SHEPHERD 1999).

Encontrando evidências empíricas que mostraram correlação positiva entre economias de escala e requerimento de capital com maiores lucros, Bain concluiu que essas características da estrutura de mercado são barreiras de entrada, de acordo com sua definição (BAIN, 1956).

Diversos autores mostraram as dificuldades de se mensurar as barreiras de entrada. Shepherd (1991) relacionou 22 barreiras de entrada, 13 exógenas e nove endógenas, mostrando a dificuldade de se mensurar essas barreiras em um estudo científico preciso. Além disso, existem outros limitadores, como descobrir quais são os entrantes potenciais, com que velocidade as barreiras podem ser superadas e qual é exatamente a extensão dessas barreiras.

Normalmente, a escala mínima eficiente (o tamanho mínimo que a empresa precisa ter para ter lucro igual a zero), os investimentos necessários em propaganda e em capital fixo são variáveis que vêm sendo utilizadas como proxy das barreiras de entrada, procurando indicar as principais dificuldades sofridas pelas novas firmas que visam entrar numa indústria específica (CARLTON; PERLOFF, 1999). Bain, citado por Shepherd (1991), recorreu a uma simples conjectura para classificar as barreiras de entrada em três categorias: pequena, média e grande.

Neste estudo, preocupou-se, basicamente, em analisar a participação e a parcela de mercado das empresas esmagadoras de cana-de-açúcar e dos distribuidores e intermediários de álcool nessa cadeia produtiva. Para se estimar a participação de mercado das unidades esmagadoras de açúcar e álcool na região Centro-Sul do País, utilizou-se o cadastro disponível na Unica, da safra de 2004/2005 à de 2008/2009. Vale lembrar que, de acordo com a Unica, a região Centro-Sul do País foi responsável por $88,74 \%$ da produção de cana-deaçúcar do País na safra 2008/2009, sendo, portanto, representativa do que acontece no Brasil. Com estes dados, calculou-se a concentração de mercado por meio da taxa de concentração das quatro maiores empresas $\left(\mathrm{C}_{4}\right)$, das oito maiores $\left(\mathrm{C}_{8}\right)$ e das vinte maiores $\left(\mathrm{C}_{20}\right)$, dadas pela soma da parcela de mercado dessas maiores empresas. Também foi utilizado o Índice de HirschmanHerfindahl (HHI), que é igual à soma do quadrado das parcelas de mercado de cada firma na indústria: 
$H H I=\sum\left(\frac{y i}{y t}\right)^{2}$

em que:

$\mathrm{y}_{\mathrm{i}}=$ participação de mercado de cada empresa

$\mathrm{y}_{\mathrm{t}}=$ total do mercado

Este índice HHI varia entre um limite reduzido de 0 e 1 (monopólio) e, quanto mais próximo de 1 , mais concentrada é a indústria.

Visando analisar não somente a concentração das unidades esmagadoras, procurou-se estimar também a concentração dos grupos empresariais do setor agroindustrial de açúcar e álcool, pois podem existir grupos dessa agroindústria que atuem não somente no esmagamento, mas também na comercialização desses produtos, como a Cosan. Assim, aplicou-se esta mesma análise de concentração ao segmento de açúcar e álcool, que fazem parte do cadastro das 400 maiores empresas do agronegócio de 2006 e 2008 e das 500 maiores de 2007, do Anuário Exame Agronegócio, e das 400 maiores empresas do agronegócio nas Melhores e Maiores da Revista Exame de 2009. Estes cadastros da Revista Exame foram utilizados porque, além de contemplar diferentes grupos empresariais do setor agroindustrial sucroalcooleiro, existem dados de empresas que não estão disponíveis em outros cadastros, como os da BM\&FBovespa, pois não são empresas Sociedades Anônimas, que, por lei, seriam obrigadas a disponibilizar esses dados. Nessa etapa, também foi levantada uma série de informações, em revistas e jornais, que complementasse essa análise quantitativa.

Essa mesma análise de concentração também foi feita para as distribuidoras de álcool no Brasil, por meio do cadastro disponível na ANP (Agência Nacional do Petróleo), órgão responsável por fiscalizar e regulamentar toda a cadeia de combustíveis do País, de 2000 a 2008.

Juntamente a essas análises, foram levantados os resultados de outros estudos, fazendo comparação e contextualização dos resultados deste trabalho. Finalmente, foram levantadas informações em jornais e revistas, como Folha de S. Paulo, Jornal da Cana, Revista Exame, Valor Econômico, Estado de S. Paulo, bem como sites de consultorias e assessorias, como PricewaterhouseCoopers (PWC) e KPMG Corporate Finance. 
720 - Fusões e Aquisições das Unidades Produtivas e da Agroindústria de Cana-de-açúcar no Brasil e nas Distribuidoras de Álcool Hidratado Etílico

\section{Resultados e discussão}

Um dos estudos nos quais se procurou, entre outras análises, avaliar o processo de concentração na agroindústria do açúcar e do álcool, foi o de Vian e Souza Lima (2005), em que a intensificação da competição e o dinamismo nas estratégias produtivas resultaram em uma redução da concentração técnica do setor. Analisando-se as médias trimestrais de moagem de cana no estado de São Paulo, observa-se que os índices de concentração $\mathrm{C}_{4}, \mathrm{C}_{8}, \mathrm{C}_{20}$ e $\mathrm{HHI}$ diminuíram de $14,94 \%, 25,25 \%, 45,67 \%$ e $0,0161 \%$, respectivamente, na safra $1991 / 92$, para $11,07 \%, 19,01 \%, 37,14 \%$ e $0,0121 \%$ na temporada $2002 / 03$.

Ainda de acordo com Vian e Souza Lima (2005), as empresas de pequeno e médio porte, visando diminuir custos, aumentaram a escala de produção e, consequentemente, houve queda na parcela de produção das processadoras líderes. Além disso, a impossibilidade de ampliar a produção nas regiões tradicionais tem forçado o surgimento de novas plantas produtivas em outras regiões. Isso fica mais claro quando se observa que a redução da concentração foi relativamente mais acentuada nas maiores indústrias, tendo o $\mathrm{C}_{4}$ diminuído $25 \%$ e o $\mathrm{C}_{20}, 20 \%$. Esse comportamento, descrito na Tabela 1, ainda é verificado.

Tabela 1: Índices de concentração das unidades produtoras de cana-de-açúcar da região Centro-Sul do Brasil

\begin{tabular}{cccccc}
\hline Safra & $\mathbf{C}_{\mathbf{4}}$ & $\mathbf{C}_{\mathbf{8}}$ & $\mathbf{C}_{\mathbf{2 0}}$ & $\mathbf{H H I}$ & $\mathbf{n}$ \\
\hline $04 / 05$ & $10,19 \%$ & $17,32 \%$ & $34,56 \%$ & 0,01117 & 135 \\
$05 / 06$ & $10,09 \%$ & $17,06 \%$ & $33,86 \%$ & 0,010919 & 140 \\
$06 / 07$ & $9,55 \%$ & $16,27 \%$ & $32,64 \%$ & 0,010352 & 150 \\
$07 / 08$ & $8,33 \%$ & $14,88 \%$ & $30,59 \%$ & 0,00939 & 165 \\
\hline $08 / 09$ & $8,09 \%$ & $14,28 \%$ & $28,70 \%$ & 0,008673 & 169 \\
\hline Var \% & $\mathbf{- 2 0 , 6 4 \%}$ & $\mathbf{- 1 7 , 5 3 \%}$ & $\mathbf{- 1 6 , 9 4 \%}$ & $\mathbf{- 2 2 , 3 6 \%}$ & \\
\hline
\end{tabular}

Fonte: Calculado pelo autor, com base nos dados da Unica.

Nota: $\mathrm{C}_{4}$ : Concentração das quatro maiores usinas

$\mathrm{C}_{8}$ : Concentração das oito maiores usinas

$\mathrm{C}_{20}$ : Concentração das 20 maiores usinas

HHI: índice Hirschman-Herfindahl

n: número de unidades produtoras de cana-de-açúcar

var \%: variação percentual dos índices Cs da safra 08/09 em relação à safra 04/05 
Segundo dados da Unica, na safra 2008/2009, a produção de cana-deaçúcar, dividida por região do País, revela que as regiões Norte e Nordeste representaram 11,26\% da produção total do País e o Centro-Sul, 88,74\%. A produção do Centro-Sul continuará a se expandir e a ser mais expressiva que a produção do Norte e Nordeste, em função da sua maior produtividade. Assim, pode-se concluir que o comportamento verificado na tabela anterior representa o que vem acontecendo no País. Entretanto, toda a análise anterior se baseia nas plantas produtivas e não nos diferentes grupos econômicos. Os dados da Tabela 2 mostram forte elevação no número de aquisições no setor sucroalcooleiro, entre 1995 e 2003. 
722 - Fusões e Aquisições das Unidades Produtivas e da Agroindústria de Cana-de-açúcar no Brasil e nas Distribuidoras de Álcool Hidratado Etílico

Tabela 2. Incorporação no setor sucroalcooleiro do Brasil (1995-2003)

\begin{tabular}{|c|c|c|c|c|}
\hline Ano & Empresa & UF & Comprador/parceiro & Tipo \\
\hline 1995 & Usina Santa Elisa & $\mathrm{SP}$ & Balli Group & JV \\
\hline 1995 & Usina Santa Lydia & $\mathrm{SP}$ & Consórcio Paulista & A \\
\hline 1996 & Usina Santa Olinda & $\mathrm{SP}$ & Grupo José Pessoa & $\mathrm{F}$ \\
\hline 1997 & Açucareira Santo Alexandre & $\mathrm{SP}$ & Ipiranga & $\mathrm{F}$ \\
\hline 1998 & Cia Açucareira São Geraldo & $\mathrm{SP}$ & Usina Santa Elisa S/A & $\mathrm{F}$ \\
\hline 1998 & Usina Diamante & $\mathrm{SP}$ & Cosan & A \\
\hline 1998 & Usina Adelaide & $\mathrm{SP}$ & Usina da Barra & A \\
\hline 1999 & Usina Sanagro & $\mathrm{SP}$ & Grupo João Pessoa & $\mathrm{F}$ \\
\hline 1999 & Usina Iracema & $\mathrm{SP}$ & Usina São Martinho & $\mathrm{F}$ \\
\hline 2000 & Ipaussu & $\mathrm{SP}$ & FBA & - \\
\hline 2000 & Usina Rafard & SP & Grupo Cosan & A \\
\hline 2000 & Usina Amália / Santa Rosa & $\mathrm{SP}$ & Usina da Pedra & A \\
\hline 2000 & Usina Benalco & $\mathrm{SP}$ & Grupo J. Pessoa & A \\
\hline 2000 & Usina Delta & MG & Carlos Lyra & A \\
\hline 2000 & Usina Cresciumal & SP & Coinbra / Dreyfus & A \\
\hline 2000 & Destilaria Vale do Rio Turvo & $\mathrm{SP}$ & José Duarte Silveira Barros & A \\
\hline 2000 & Indústria Açuc. São Francisco & $\mathrm{SP}$ & Union Sucr et Dest Agricoles & A \\
\hline 2001 & Alcoolvale Dest Vale do Quitéria S/A & MS & Unialco S/A Açúcar e Álcool & A \\
\hline 2001 & Refinadora Catarinense/Usati & $\mathrm{SC}$ & Glencore & A \\
\hline 2001 & Açucareira da Serra & $\mathrm{SP}$ & Grupo Cosan & A \\
\hline 2001 & Usina Alcomira & SP & Márcio José Pavan & A \\
\hline 2001 & Univalen/Ganabara Agro-Industrial & $\mathrm{SP}$ & FBA & A \\
\hline 2001 & Destilaria Água Limpa & $\mathrm{SP}$ & Grupo Petribu & A \\
\hline 2001 & Açúcar Guarani & $\mathrm{SP}$ & Béghin-Say & A \\
\hline 2001 & Usina São José & $\mathrm{SP}$ & Grupo Antônio Farias & A \\
\hline 2001 & Usina Luciânia & MG & Coinbra / Dreyfus & A \\
\hline 2001 & Usina Santo Antônio & $\mathrm{SP}$ & FBA & Arr \\
\hline 2002 & Usina Bela Vista & SP & Usina Bazan & A \\
\hline 2002 & Usina Santa Cruz & $\mathrm{RJ}$ & Grupo José Pessoa & A \\
\hline 2002 & Usina da Barra & $\mathrm{SP}$ & Grupo Cosan & A \\
\hline 2002 & Gasa & $\mathrm{SP}$ & Grupo Cosan & A \\
\hline 2002 & Junqueira & $\mathrm{SP}$ & Grupo Cosan & - \\
\hline 2002 & Maluf & $\mathrm{SP}$ & Dulcini & - \\
\hline 2002 & Alcoazul & $\mathrm{SP}$ & Grupo José Pessoa & - \\
\hline 2003 & Quissamã & $\mathrm{RJ}$ & Grupo José Pessoa & - \\
\hline
\end{tabular}

Fonte: KPMG, extraído do Agrianual (Anuário Estatístico da Agricultura Brasileira), 2003 JornalCana 2002/2003 e Valor Econômico 2003, extraído de Vegro et al., 2003. Nota: JV = joint venture; $\mathrm{F}$ = fusão; $\mathrm{A}$ = aquisição; e Arr = arrendamento 
Em 2004, a KPMG Corporate Finance registrou cinco casos de aquisição neste setor e o grupo Cosan e o FBA foram os principais compradores. Representantes de empresas de consultoria da KPMG e da PWC, nesse período, apontavam maior potencial de negócios no segmento sucroalcooleiro, pelo fato de o setor ser altamente pulverizado, bem como pela vitória do Brasil contra os subsídios europeus ao açúcar na OMC (Organização Mundial do Comércio), que criou expectativa de ampliar a fatia do Brasil no mercado mundial de açúcar, atraindo investidores estrangeiros. Além disso, problemas de sucessão nas empresas, grande parte delas familiares, podem ter estimulado essas operações. Juntamente a esse aumento de fusões e aquisições, observou-se, nesse período, um aumento da participação de capital estrangeiro nesse setor, que estreou a partir de 2000, com a entrada dos grupos Louis Dreyfus Commodities (LDC) e Tereos (antiga Béghin-Say) no Brasil. Em 2006, as empresas estrangeiras respondiam por 4,5\% da produção nacional de cana, ou 18,5 milhões de toneladas, e tinham 11 unidades (Unica, 2006).

De acordo com a KPMG Corporate Finance, nos anos de 2006, 2007, 2008 e 2009, ocorreram nove, 25, 14 e seis fusões e aquisições, respectivamente, no setor de açúcar e álcool. Dados da Unica mostraram que 67 grupos econômicos sucroalcooleiros do Centro-Sul do País detinham 154 unidades produtoras na safra 2006/07, que processaram cerca de 73,23\% da produção do Centro-Sul, ou 273,5 milhões de toneladas.

Em 2007, os principais compradores foram grandes grupos e fundos estrangeiros, responsáveis por $70 \%$ das transações realizadas. Somente nos três primeiros meses de 2007, o Banco Central registrou o ingresso de US $\$ 6,5$ bilhões, aumento de $66 \%$ em relação ao mesmo período do ano anterior, sendo o álcool o maior responsável por este aumento recorde. Depois da forte entrada de investimentos registrada em 2007, os negócios perderam força em 2008, por conta da crise financeira global. Entretanto, as companhias estrangeiras, como a multinacional americana Bunge, a espanhola Abengoa, o asiático Noble Group, as francesas Louis Dreyfus Commodities (LDC) e Tereos, continuaram adquirindo usinas no País naquele ano, fazendo com que o setor sucroalcooleiro figurasse entre aqueles com maior número de fusões e aquisições, e fosse responsável por $18 \%$ dessas operações, segundo a PWC.

Com a crise financeira internacional no final de 2008, muitas usinas vêm encontrando dificuldades para honrar seus compromissos financeiros, atrasando o pagamento aos seus fornecedores de cana-de-açúcar e buscando a negociação com bancos para amenizar suas dificuldades de caixa. Além disso, os ativos das usinas estão relativamente baratos. A usina Santelisa Vale, por exemplo, em busca de recursos financeiros, foi vendida para a empresa francesa Louis Dreyfus Commodities (LDC). A Cosan recebeu capital da Gávea Investimento 
724 - Fusões e Aquisições das Unidades Produtivas e da Agroindústria de Cana-de-açúcar no Brasil e nas Distribuidoras de Álcool Hidratado Etílico

e de outros fundos, além de fazer uma joint-venture com a empresa Shell.

As empresas maiores estão se capitalizando e comprando as menores, até gerarem grandes operadoras do setor. De acordo com muitos analistas, isso é importante pelo fato de os preços oscilarem bastante nesse mercado, fazendo com que a rentabilidade dessas empresas varie muito de uma safra a outra. $\mathrm{O}$ comportamento dos preços mensais da saca de $50 \mathrm{~kg}$ de açúcar, no período de janeiro de 1998 a dezembro de 2008, à vista ou a prazo, incluindo os impostos ICMS (7\%), PIS/Cofins (9,25\%), está ilustrado na Figura 1. Na Figura 2 observase o comportamento dos preços semanais do litro do álcool hidratado e do etílico, sem impostos (até a semana encerrada em 26/9/2008, o indicador semanal do álcool hidratado outros fins incluía 9,25\% de PIS/Cofins), de julho de 2000 até março de 2010. Percebe-se, em ambos os gráficos, que os preços oscilaram bastante, proporcionado períodos com faturamento maior e outros com faturamento menor para as usinas produtoras.

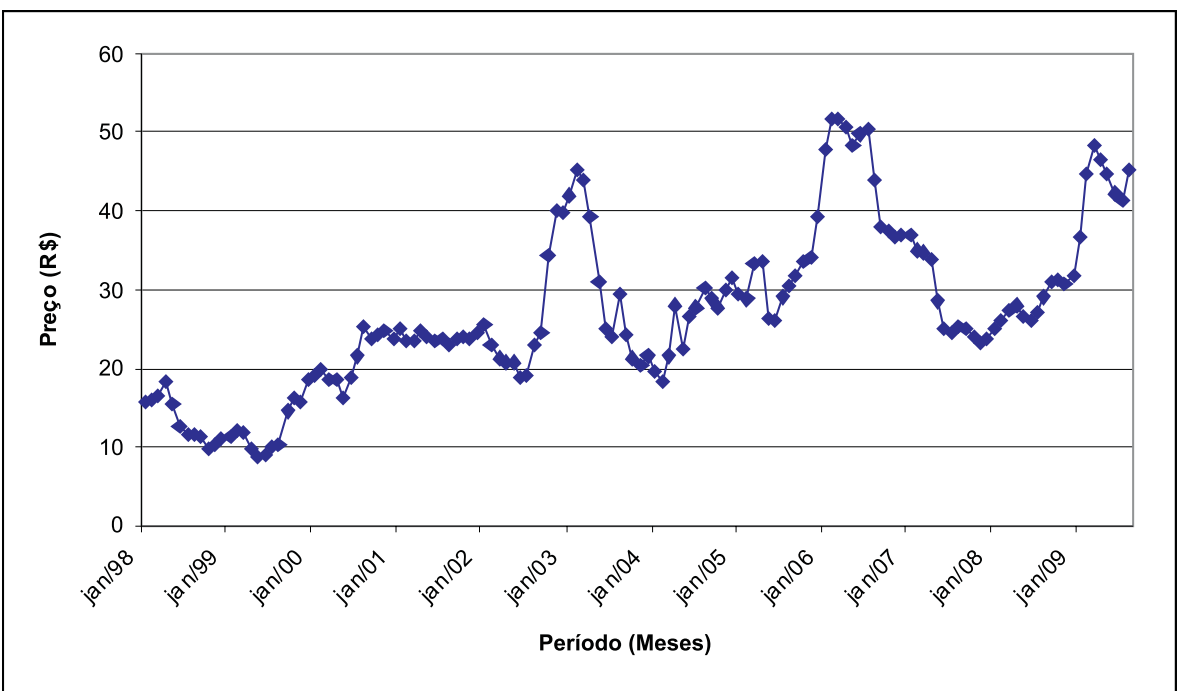

Figura 1. Preço mensal da saca de $50 \mathrm{~kg}$ do açúcar cristal no Brasil - janeiro de 1998 a dezembro de 2008

Fonte: Indicador Diário de Açúcar Cristal CEPEA/ESALQ - São Paulo. 


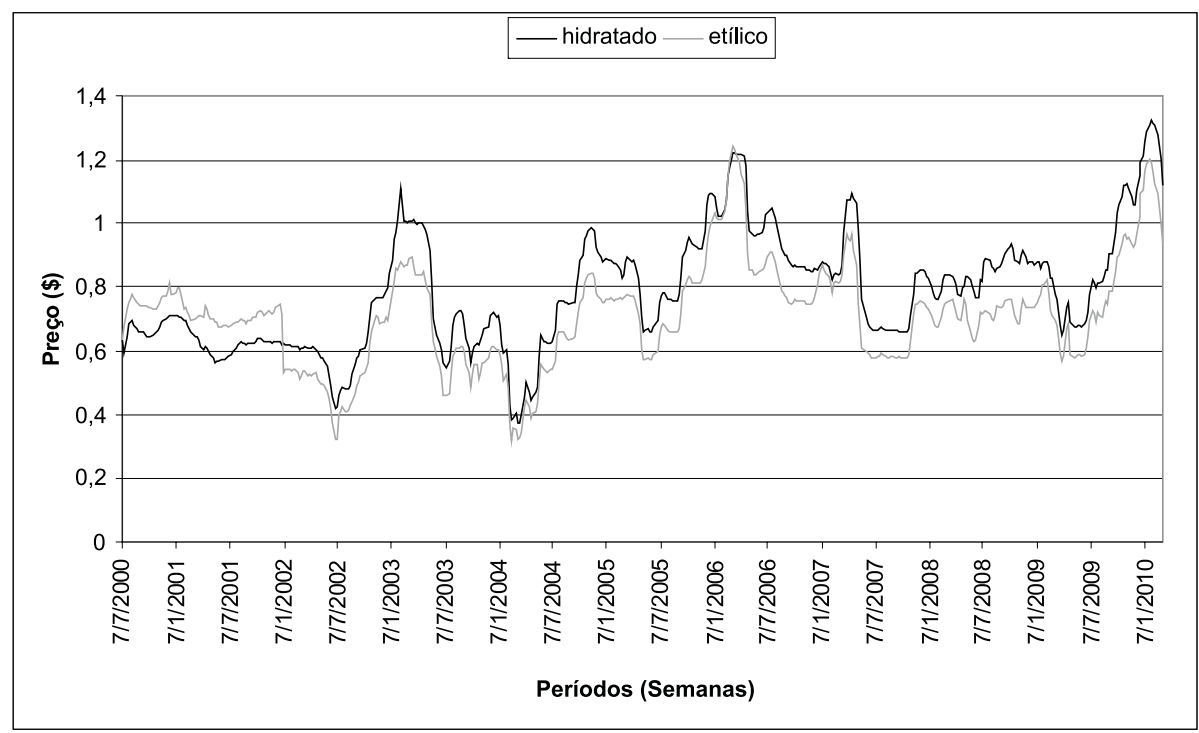

Figura 2. Preço semanal do litro do álcool hidratado e etílico de São Paulo - julho de 2000 a março de 2010

Fonte: Indicador Semanal de Álcool anidro e hidratado CEPEA/ESALQ - São Paulo.

Soma-se a isso o fato de que o atual processo de concentração da indústria, juntamente ao aumento da escala de produção, pode eliminar as barreiras para a promoção da bioeletricidade sucroalcooleira proveniente das usinas. $\mathrm{O}$ setor sucroalcooleiro é hoje autossuficiente em suas necessidades energéticas, em função da integração vertical e do avanço tecnológico, que vem aumentado a capacidade de geração de energia elétrica acima da necessidade do autoconsumo. Entretanto, é necessário que haja aumento da escala de produção para que se viabilize economicamente a bioeletricidade nas usinas, e o processo de fusão e aquisição pode contribuir muito para esse resultado. A Unica estima que a atual participação de $1 \%$ da bioeletricidade na receita da usina pode passar para $16 \%$ na safra $2015 / 16$, em um período em que o processo de fusões e aquisições na indústria sucroalcooleira esteja ocorrendo de forma bastante intenso (CASTRO; DANTAS, 2008).

De acordo com a Unica, em 2009, o setor de açúcar e álcool respondeu por cerca de $23 \%$ das transações na indústria de alimentos e agronegócio. Com as variações expressivas de preço do açúcar e do álcool e outras condições adversas de mercado, inclusive em relação à escassez de crédito e não existência de linhas para o refinanciamento de operações já contratadas, o setor ficou 
726 - Fusões e Aquisições das Unidades Produtivas e da Agroindústria de Cana-de-açúcar no Brasil e nas Distribuidoras de Álcool Hidratado Etílico

diante de uma fase de consolidação. Algumas fusões, aquisições e parcerias que ocorreram entre 2004 e 2010 estão listadas na Tabela 3, podendo-se observar a presença cada vez mais intensa de grupos estrangeiros.

Tabela 3. Principais transações no setor sucroalcooleiro, de 2004 a 2010

\begin{tabular}{|c|c|c|c|}
\hline Ano & Empresa & $\begin{array}{l}\text { Comprador / } \\
\text { parceiro }\end{array}$ & Tipo \\
\hline 2004 & $\begin{array}{l}\text { São Carlos Usina } \\
\text { Açucareira de } \\
\text { Jaboticabal }\end{array}$ & $\begin{array}{l}\text { Louis Dreyfus } \\
\text { Commodities } \\
\text { (LDC) }\end{array}$ & $\begin{array}{l}\text { Transferência de } 100 \% \text { da operação industrial de açúcar e } \\
\text { álcool para a Louis Dreyfus. }\end{array}$ \\
\hline 2004 & Açúcar Guarani & Tereos & $\begin{array}{l}\text { Tereos comprou os } 35,8 \% \text { de participação restante do grupo } \\
\text { italiano Edison, tornando -se o único acionista da Açúcar } \\
\text { Guarani, com duas usinas no interior paulista. }\end{array}$ \\
\hline 2004 & Usati & Grupo Cosan & $\begin{array}{l}\text { Transferência de } 100 \% \text { da operação de refino de açúcar para } \\
\text { a Cosan. }\end{array}$ \\
\hline 2006 & Tavares de Melo & $\begin{array}{l}\text { Louis Dreyfus } \\
\text { Commodities }\end{array}$ & $\begin{array}{l}\text { O grupo francês Louis Dreyfus comprou quatro usinas do } \\
\text { grupo pernambucano Tavares de Melo. }\end{array}$ \\
\hline 2006 & Monte Alegre & Adecoagro & $\begin{array}{l}\text { O investidor húngaro George Soros (por meio da empresa } \\
\text { Adecoagro) fechou, em fevere iro, a compra da usina Monte } \\
\text { Alegre, em Minas Gerais. }\end{array}$ \\
\hline 2006 & $\begin{array}{l}\text { Cristal Destilaria } \\
\text { Autônoma de } \\
\text { Álcool (Cridasa) }\end{array}$ & Evergreen & $\begin{array}{l}\text { O grupo inglês Evergreen adquiriu o controle acionário da } \\
\text { Cridasa. }\end{array}$ \\
\hline 2006 & Cevasa & Cargil & $\begin{array}{l}\text { A norte-americana Cargill comprou essa usina de álc ool no } \\
\text { interior de São Paulo. }\end{array}$ \\
\hline $\begin{array}{l}2006 / \\
2007\end{array}$ & $\begin{array}{l}\text { Cridasa, Disa, } \\
\text { Alcana, Paraíso e } \\
\text { Usinavi, Ibirálcool, } \\
\text { Cepar e Agromar }\end{array}$ & Infinity Bio-Energy & $\begin{array}{l}\text { Multinacional com ações negociadas na Bolsa de Londres, } \\
\text { adquiriu destilarias nos estados de Minas Gerais, Espírito } \\
\text { Santo, Bahia e Rio Grande do Norte. }\end{array}$ \\
\hline 2007 & Vale do Rosário & $\begin{array}{l}\text { Santa Elisa Açúcar } \\
\text { e Álcool }\end{array}$ & Processo de fusão entre as duas. \\
\hline 2007 & Destilaria Alcídia & ETH Bioenergia & $\begin{array}{l}\text { Alienação da companhia para a ETH Bioenergia, controlada } \\
\text { pela Odebrecht Açúcar e Álcool. }\end{array}$ \\
\hline 2007 & ETH Bioenergia & Sojitz Corporation & A japonesa Sojitz comprou participação na ETH Bioenergia. \\
\hline 2007 & Alcoolvale & $\begin{array}{l}\text { Clean Energy Brazil } \\
\text { (CEB) }\end{array}$ & $\begin{array}{l}\text { O CEB adquiriu 33\% da holding Unialco MS, que controla a } \\
\text { usina Alcoolvale. }\end{array}$ \\
\hline 2007 & $\begin{array}{l}\text { Grupo Dedini Agro } \\
\text { Açúcar e Álcool }\end{array}$ & Abengoa & Aquisição. \\
\hline
\end{tabular}




\section{Paulo Henrique de Lima Siqueira \& • 727 Luiz Gonzaga de Castro Junior}

\begin{tabular}{|c|c|c|c|}
\hline 2008 & Benálcool & Grupo Cosan & $\begin{array}{l}\text { A Cosan comprou a usina Benálcool, que pertencia ao grupo } \\
\text { J. Pessoa. }\end{array}$ \\
\hline 2008 & Tropical Bioenergia & $\mathrm{BP}$ & $\begin{array}{l}\text { A britânica BP comprou fatia de } 50 \% \text { na Tropical } \\
\text { Bioenergia. }\end{array}$ \\
\hline 2008 & Usina Eldorado & ETH Bioenergia & $\begin{array}{l}\text { A ETH Bioenergia adquiriu, por US\$ } 350 \text { milhões, a Usina } \\
\text { Eldorado. }\end{array}$ \\
\hline 2008 & Esso & Cosan & $\begin{array}{l}\text { O grupo Cosan constituiu a Cosan Combustíveis e } \\
\text { Lubrificantes (CCL), para adquirir a Esso do Brasil e se } \\
\text { tornar o único grupo sucroalcooleiro a integrar o } \\
\text { concentrado mercado de distribuição de combustívei s e } \\
\text { lubrificantes. }\end{array}$ \\
\hline 2009 & Açúcar Guarani & Tereos & $\begin{array}{l}\text { A francesa Tereos aumentou sua fatia no Guarani, com } \\
\text { aporte de R\$ } 309 \text { milhões. }\end{array}$ \\
\hline 2009 & Usaciga & $\begin{array}{l}\text { Agrocana } \\
\text { Participações Ltda. }\end{array}$ & $\begin{array}{l}\text { A investidora em biocombust íveis Clean Energy Brazil } \\
\text { vendeu } 49 \% \text { de suas participações n a Usaci ga por } 8,7 \\
\text { milhões de dólares. }\end{array}$ \\
\hline 2009 & Brenco & ETH Bioenergia & $\begin{array}{l}\text { União entre ETH Bioenergia e a Brenco . A Odebrecht } \\
\text { passou a deter } 65 \% \text { do capital da nova companhia e os } \\
\text { acionistas da Brenco, } 35 \% \text {. }\end{array}$ \\
\hline 2009 & $\begin{array}{l}\text { Usina Santelisa } \\
\text { Vale }\end{array}$ & $\begin{array}{l}\text { Louis Dreyfus } \\
\text { Commodities } \\
\text { (LDC) }\end{array}$ & $\begin{array}{l}\text { Aquisição de } 60 \% \text { da Santelisa Vale. A nova joint venture, } \\
\text { chamada de LDC-SEV, vai controlar } 13 \text { unidades de açúcar } \\
\text { e etanol e tem capacidade anual de moagem de } 40 \text { milhões } \\
\text { de toneladas de cana. }\end{array}$ \\
\hline 2009 & Vale do Ivaí & $\begin{array}{l}\text { O grupo indiano } \\
\text { Shree Renuka } \\
\text { Sugars Ltd. }\end{array}$ & $\begin{array}{l}\text { A co mpra das duas unidades sucroalcooleiras da Vale do } \\
\text { Ivaí Açúcar e Álcool, em São Pedro do Ivaí (PR). }\end{array}$ \\
\hline 2009 & Manacá & Clarion & Aquisição de ativos da destilaria de álcool Manacá. \\
\hline 2009 & Nova América & Grupo Cosan & Aquisição. \\
\hline $\begin{array}{c}2009 / \\
2010\end{array}$ & Grupo Moema & Bunge Ltd. & $\begin{array}{l}\text { Detém } 100 \% \text { de participação em três usinas de açúcar e } \\
\text { álcool, proprietária única das usinas Moema, Frutal e } \\
\text { Ouroeste, } 70 \% \text { da usina Guariroba e com aproximadamente } \\
44 \% \text { da Itapagipe. }\end{array}$ \\
\hline 2010 & Shell & Grupo Cosan & $\begin{array}{l}\text { Formação de uma joint-venture para reunir operações de } \\
\text { açúcar, etanol, distribuição de combustíveis e pesquisa. }\end{array}$ \\
\hline
\end{tabular}


728 - Fusões e Aquisições das Unidades Produtivas e da Agroindústria de Cana-de-açúcar no Brasil e nas Distribuidoras de Álcool Hidratado Etílico

\begin{tabular}{c|l|l|l}
\hline 2010 & $\begin{array}{l}\text { Total Agroindú stria } \\
\text { Canavieira }\end{array}$ & Petrobras & $\begin{array}{l}\text { 40,4\% de participação na usina de etanol Total } \\
\text { Agroindústria Canavieira, por R\$ } 150 \text { milhões. }\end{array}$ \\
\hline 2010 & $\begin{array}{l}\text { Equipav Açúcar e } \\
\text { Álcool }\end{array}$ & $\begin{array}{l}\text { Grupo indiano } \\
\text { Shree Renuka } \\
\text { Sugars Ltd. }\end{array}$ & $\begin{array}{l}\text { Aquisição de 50,8\% ; tem usinas nas cidades paulistas de } \\
\text { Promissão e Brejo Alegre. }\end{array}$ \\
\hline 2010 & Usina Vertente & Açúcar Guarani & $\begin{array}{l}\text { A Açúcar Guarani, do grupo francês Tereos, adquiriu 50\% } \\
\text { da Usina Vertente, do Grupo Hu mus no município de } \\
\text { Guaraci ( SP). Essa transação permitirá ganhos de } \\
\text { produtividade industrial, agrícola e de eficiência. A Usina } \\
\text { Vertente era parte das usinas do Grupo Moema e foi a única } \\
\text { que a Bunge não incorporou. }\end{array}$ \\
\hline
\end{tabular}

Fonte: PWC, KPMG, e os jornais Valor Econômico, Folha de São Paulo, JornalCana, além de diferentes sites de especialistas e consultores no setor sucroalcooleiro.

Os dados da Tabela 3 demonstram a presença cada vez mais intensa de estrangeiros no processo de fusões e aquisições das usinas nacionais. A norteamericana Kidd\&Company detém o controle da usina Coopernavi e participa da empresa Infinity Bio-Energy, em conjunto com a corretora Merrill Lynch; a inglesa Infinity Bio-Energy já é dona de cinco usinas no País; o grupo francês Louis Dreyfus Commodities (LDC) controla as usinas Luciânia, Cresciumal e quatro usinas do grupo pernambucano Tavares de Melo; o grupo Tereos, também de origem francesa, tem 6,3\% de participação na Cosan, 47,5\% na FrancoBrasileira de Açúcar e 69,3\% na Açúcar Guarani. A composição do capital das sete maiores empresas sucroalcooleiras brasileiras é mostrada na Tabela 4. 
Paulo Henrique de Lima Siqueira \& $\cdot \mathbf{7 2 9}$ Luiz Gonzaga de Castro Junior

Tabela 4. Participação nacional ou estrangeira na composição do capital das sete maiores empresas sucroalcooleiras

\begin{tabular}{|c|c|c|}
\hline Empresa & $\begin{array}{l}\text { Capacidade } \\
\text { instalada em bilhões } \\
\text { de litros }\end{array}$ & Participação estrangeira na parcela de capital \\
\hline Cosan & 2,967 & $\begin{array}{l}\text { Inglês, francês e holandês: cerca de } 70 \% \text { de seus ativos vão } \\
\text { constituir, com a anglo -holandesa Shell, duas empresa s; a joint- } \\
\text { venture foi anunciada em } 2010 \text {. }\end{array}$ \\
\hline $\begin{array}{l}\text { LDC e Santelisa } \\
\text { Vale }\end{array}$ & 1,422 & $\begin{array}{l}\text { Francês e americano: a francesa Louis Dreyfus Commodities } \\
\text { (LDC) assumiu a Santelisa Vale em 2009. A companhia tem 61\% } \\
\text { do capital da LCD e Goldman Sachs. }\end{array}$ \\
\hline Tereos (Guarani) & 1,018 & $\begin{array}{l}\text { Francês: a francesa Tereos aumentou su a participação na Açúcar } \\
\text { Guarani para } 69,3 \% \text {, em } 2009 \text {. }\end{array}$ \\
\hline São Martinho & 0,910 & $\begin{array}{l}\text { Americano: sem participação estrangeira, mas negocia com a } \\
\text { americana Amyris. }\end{array}$ \\
\hline $\begin{array}{l}\text { Bunge (mais } \\
\text { Moema) }\end{array}$ & 0,881 & $\begin{array}{l}\text { Americano: } 100 \% \text { da americana Bunge, após incorporar o Grupo } \\
\text { Moema, da família Biaggi. }\end{array}$ \\
\hline Santa Terezinha & 0,722 & Sem participação estrangeira. \\
\hline ETH Bioenergia & 0,672 & $\begin{array}{l}\text { Japonês: a Brenco foi incorporada pela ETH, que terá } 65 \% \text { da } \\
\text { empresa resultante da fusão, a ETH Bioenergia. A ETH é } 33 \% \text { da } \\
\text { japonesa Sojtz e } 67 \% \text { da Odebrecht. }\end{array}$ \\
\hline
\end{tabular}

Fonte: Folha de S. Paulo, segundo dados da Bloomberg New Energy Finance (2010).

O Grupo Cosan é responsável por aproximadamente $10 \%$ do processamento de cana-de-açúcar do País, congregando 23 unidades industriais, além de ter sido pioneiro na abertura do seu capital ${ }^{9}$ junto à BM\&FBovespa, em 2005, seguido pelos grupos São Martinho, Garani e Nova América, em 2007. A aquisição do grupo Nova América, em 2009, representou a transferência de um controle baseado na família para outro, fundamentado no valor do acionista, uma vez que a família Resende Barbosa, antiga proprietária, passou a ter aproximadamente $11 \%$ do total do capital da empresa (MUNDO NETO, 2009). Essa aquisição feita pela Cosan retrata muito bem a mudança da forma de gestão resultante das fusões e aquisições que vêm ocorrendo no setor: administração de tradição familiar para uma administração profissionalizada,

\footnotetext{
9 As empresas fazem abertura de capital quando passam a ser sociedades anônimas, ou seja, vendem ações no mercado de capitais, que representam uma parcela do seu capital, que é vendida a terceiros nesse mercado. Uma das implicações desse processo é que as empresas passam a ser obrigadas a divulgar mais seus números financeiros, para manter informados os novos acionistas ou sócios.
} 
730 - Fusões e Aquisições das Unidades Produtivas e da Agroindústria de Cana-de-açúcar no Brasil e nas Distribuidoras de Álcool Hidratado Etílico

também chamada de governança corporativa ${ }^{10}$.

Para muitos analistas, o ritmo de fusões e aquisições no setor de cana deve se manter, mas há obstáculos, como a composição societária das empresas, muitas delas com forte tradição familiar, e outros problemas contábeis, visto que poucas usinas de cana-de-açúcar fizeram a abertura de seu capital. Mesmo com a abertura do seu capital, a Cosan, por exemplo, teve muitos problemas com os pequenos investidores, pois também abriu capital nos Estados Unidos, aumentando a parcela de capital dos proprietários e, automaticamente, diminuindo o poder de decisão dos outros acionistas, prejudicando-os.

Apesar desses contratempos, de acordo a KPMG Corporate Finance, existe uma pulverização muito grande no setor. Os 20 maiores grupos em operação no País ainda não detêm nem $50 \%$ da produção total de cana. Esse comportamento pode ser confirmado quando se analisa a concentração do mercado das maiores empresas do agronegócio de açúcar e álcool (Tabela 5).

Tabela 5. Índices de concentração das maiores empresas do agronegócio do açúcar e do álcool

\begin{tabular}{cccccc}
\hline Ano & $\mathbf{C}_{\mathbf{4}}$ & $\mathbf{C}_{\mathbf{8}}$ & $\mathbf{C}_{\mathbf{2 0}}$ & $\mathbf{H H I}$ & $\mathbf{n}$ \\
\hline 2006 & $44,69 \%$ & $57,59 \%$ & $82,22 \%$ & 0,087348 & 38 \\
2007 & $34,20 \%$ & $44,88 \%$ & $68,07 \%$ & 0,057609 & 62 \\
2008 & $31,37 \%$ & $43,96 \%$ & $65,33 \%$ & 0,044070 & 75 \\
\hline 2009 & $31,86 \%$ & $45,89 \%$ & $68,17 \%$ & 0,046161 & 62 \\
\hline var \% & $\mathbf{- 2 8 , 7 1 \%}$ & $\mathbf{- 2 0 , 3 2 \%}$ & $\mathbf{- 1 7 , 0 8 \%}$ & $\mathbf{- 4 7 , 1 5 \%}$ & \\
\hline
\end{tabular}

Fonte: Calculado pelo autor com base nos dados das 400 maiores empresas do agronegócio de cana-de-açúcar de 2006 e 2008, das 500 maiores de 2007 e das 400 maiores empresas do agronegócio de cana-de-açúcar pelo Anuário Exame Agronegócio e Maiores e Melhores 2009.

Nota: $\mathrm{C}_{4}$ : Concentração das quatro maiores empresas

$\mathrm{C}_{8}$ : Concentração das oito maiores empresa

$\mathrm{C}_{20}$ : Concentração das 20 maiores empresas

HHI: índice Hirschman-Herfindahl

n: número empresas de cana de açúcar

var \%: variação percentual dos índices Cs do ano 2009 em relação à 2006

\footnotetext{
${ }^{10} \mathrm{O}$ capital das grandes empresas é composto por diferentes acionistas que passam a ter representes no conselho administrativo, selecionando e fiscalizando os administradores. Quanto maior a parcela de capital, maior a quantidade de representantes no conselho administrativo que um acionista pode ter.
} 
Os dados dessa tabela mostram que existe pouca concentração dessas empresas, ainda que mais significativa do que das unidades produtoras, e ela ainda vem diminuindo. Assim, observa-se a pouca concentração, mesmo quando se consideram os grupos desse agronegócio, o que mostra que ainda existem muitas possibilidades de que novas fusões e aquisições na agroindústria do açúcar e do álcool ocorram, já que ela ainda se encontra muito pulverizada.

Apesar dessa pequena concentração na agroindústria do açúcar e do álcool, o mesmo não se pode dizer das distribuidoras de álcool etílico hidratado, conforme dados da Tabela 6.

Tabela 6. Índices de concentração das distribuidoras nas vendas nacionais de álcool etílico hidratado, entre 2000 e 2008

\begin{tabular}{cccccc}
\hline Ano & C4 & C8 & C20 & HHI & n \\
\hline 2000 & 40,07 & 60,35 & 78,73 & 0,0573 & 159 \\
2001 & 40,82 & 60,16 & 80,06 & 0,059 & 156 \\
2002 & 41,34 & 63,71 & 84,01 & 0,065 & 150 \\
2003 & 40,27 & 60,11 & 79,55 & 0,0617 & 158 \\
2004 & 41,20 & 58,79 & 75,90 & 0,0596 & 169 \\
2005 & 48,54 & 64,09 & 79,25 & 0,0746 & 162 \\
2006 & 41,46 & 62,65 & 81,23 & 0,0624 & 153 \\
2007 & 47,81 & 63,55 & 83,61 & 0,0744 & 159 \\
2008 & 49,93 & 63,21 & 82,79 & 0,0795 & 156 \\
\hline var \% & $\mathbf{2 4 , 6 0}$ & $\mathbf{4 , 7 4}$ & $\mathbf{5 , 1 5}$ & $\mathbf{3 8 , 7 4}$ & \\
\hline TGC & $\mathbf{9 , 0 2} * *$ & $\mathbf{2 , 2 5}{ }^{\text {ns }}$ & $\mathbf{1 , 3 8}{ }^{\text {ns }}$ & $\mathbf{1 3 , 1 1 * *}$ & \\
\hline
\end{tabular}

Fonte: Calculado pelo autor, com base nos dados da ANP.

Nota: $\mathrm{C}_{4}$ : Concentração das quatro maiores distribuidoras

$\mathrm{C}_{8}$ : Concentração das oito maiores distribuidoras

$\mathrm{C}_{20}$ : Concentração das 20 maiores distribuidoras

HHI: índice Hirschman-Herfindahl

n: número de distribuidoras

var \%: variação percentual dos índices Cs do ano de 2000 em relação à 2008

TGC: Taxa geométrica de crescimento

** significativo a $5 \%$, ns não significativo. 
732 - Fusões e Aquisições das Unidades Produtivas e da Agroindústria de Cana-de-açúcar no Brasil e nas Distribuidoras de Álcool Hidratado Etílico

A concentração das distribuidoras tem sido crescente nesses anos. $\mathrm{O} \mathrm{C}_{4}$, por exemplo, aumentou de pouco mais de $40 \%$ em 2000 , para $50 \%$ em 2008 , e apresentou taxa geométrica de crescimento de $9,02 \%$ nesse período, com $5 \%$ de significância. Pode-se dizer que, nesse setor, existe moderada concentração e esse índice vem aumentando nos últimos anos.

Assim, observa-se que os grupos a jusante na comercialização de álcool são relativamente concentrados, podendo exercer certo poder de oligopólio sobre os agentes a montante, no caso, a agroindústria produtora de açúcar e álcool. Portanto, pode existir uma preocupação por parte da agroindústria de açúcar e álcool em buscar novas estratégias para superar esses desafios.

\section{Conclusões}

O processo de fusão e aquisição, que teve início praticamente no início dos anos 90 , tem se intensificado na economia brasileira nos últimos anos. $\mathrm{O}$ setor de alimentos é o mais importante representante desse cenário. Nesse contexto, a agroindústria produtora de açúcar e álcool também tem passado por esse processo, principalmente depois da queda da intervenção do governo.

Apesar desse processo de fusões e aquisições, a agroindústria do açúcar e do álcool ainda está muito pulverizada; os quatro maiores grupos não concentram mais do que $31,86 \%$ do mercado em 2009 , sinalizando para a possibilidade de novas aquisições e fusões, principalmente depois da crise econômica mundial, que tem limitado o acesso ao crédito. Além disso, as empresas estrangeiras têm se interessado cada vez mais em investir nas empresas nacionais de açúcar e álcool, sendo as grandes responsáveis pelo processo de fusões e aquisições a partir do ano de 2000.

Por outro lado, os distribuidores são bastante concentrados, o que pode comprometer a competitividade dessa agroindústria diante desses agentes a jusante.

Diante de todos esses desafios, pode-se dizer que, provavelmente, o processo de fusão e aquisição na agroindústria de açúcar e álcool deve se intensificar nos próximos anos, com a participação de grandes empresas nacionais e estrangeiras.

Novos estudos devem ser desenvolvidos para avaliar como esse processo pode influenciar, positiva ou negativamente, outros elementos a jusante e a montante da cadeia agroindustrial da cana-de-açúcar. 


\section{Referências Bibliográficas}

AGRIANUAL 2002. Anuário Estatístico da Agricultura Brasileira. São Paulo, 2002.

AGRIANUAL 2003. Anuário Estatístico da Agricultura Brasileira. São Paulo, 2003.

ANP -Agência Nacional do Petróleo. Disponível em: www.anp.gov.br.

BAIN, J. S. Barriers to new competition. Harvard University Press, Cambridge MA, 1956

BELIK, W.; RAMOS, P.; VIAN, C. E. F. Mudanças Institucionais e seus Impactos nas Estratégias dos Capitais do Complexo Agroindutrial Canavieiro no CentroSul do Brasil. In: Congresso Brasileiro de Economia e Sociologia Rural, 36, 1998. Poços de Caldas. Anais. Brasília: SOBER, 1998, p. 519-532

CARLTON, D. W. PERLOFF, J. M. Modern Industrial Organization. Third Edition. New York: Addison Wesley Longman, 1999. 780p.

CASTRO, N. J. de.; DANTAS, G. de A. Fusões e aquisições no setor sucroalcooleiro e a promoção da bioeletricidade. GESEL - Grupo de Estudos do setor Elétrico. 2008. 6 p.

CERTO, S.; PETER, J. P. MARCONDES, R. C.; CÉSAR, A. M. R. Administração Estratégica: Planejamento e implantação da estratégia. 2. ed. São Paulo: Pearson Education do Brasil, 2005.

COELHO, C. N. O Princípio do Desenvolvimento Sustentável na Agricultura Brasileira. Revista de Política Agrícola. Ano VII, n. 2, Abr./Jun. 1998, p. 716

EID, F.; PINTO, S. S. Dinâmica Recente da Centralização de Capitais e da Restruturação de Empregos na Agroindústria Canavieira Nordestina. Disponível em: <www.race.nuca.ie.ufrj.br/abet/3reg/18.doc> [S.I.: s.n., 199_]. p. 1-11. 
734 - Fusões e Aquisições das Unidades Produtivas e da Agroindústria de Cana-de-açúcar no Brasil e nas Distribuidoras de Álcool Hidratado Etílico

FAHEY, L.; RANDALL, R. M. MBA Curso Prático: Administração Estratégica. Rio de Janeiro: Campos, 1999.

KPMG Corporate Finance. Fusões \& Aquisições no Brasil. Análise dos anos 90. [S.I.: s.n], Fevereiro de 2001, 15p.

LAGES, A. M. G. A Diferenciação Tecnológica na Indústria SucroAlcooleira do Brasil. 1993. Dissertação (Mestrado pela CME/PIMES/UFPE) - Universidade Federal de Pernambuco. Pernambuco: UFPE, 1993. 199p.

MARJOTTA-MAISTRO, M.C.; BURNQUIST, H.L. A Avaliação do fornecimento de Açúcar para as Indústrias Alimentícias do Estado de São Paulo: Uma Pesquisa de Mercado. In: Congresso Brasileiro de Economia e Sociologia Rural, 36, 1998, Poços de Caldas. Anais. Brasília: SOBER, 1998, p. 599-609

MORAES, M. A. F. D.; SILVEIRA, L. T. A Comercialização do Álcool Combustível no Período Posterior à Desregulamentação do Setor Sucroalcooleiro. In. Congresso Brasileiro de Economia e Sociologia Rural, 41, 2003. Juiz de Fora. Anais Brasília: SOBER, 2003

MUNDO NETO, M. De sucroalcooleiro a sucroenergético: a construção de um campo organizacional. In.: $\mathbf{3 3}^{\circ}$ Encontro Anual da ANPOCS. Caxambu, outubro de 2009.

NASCIMENTO, R. C. Investimento agroindustrial e capital estrangeiro no Brasil: $O$ caso do setor de laticínios. Tese (Mestrado em Economia Rural) - Universidade Federal de Viçosa. Viçosa: UFV, 1999. 106p.

OLIVEIRA, D. P. R. Administração Estratégica na Prática: a competitividade para administrar o futuro das empresas. 5. ed. São Paulo: Atlas, 2007

REVISTA EXAME. Anuário Agroindustrial 2006/2007 a 2008/2009

REVISTA EXAME. Melhores e Maiores 2009.

REVISTA EXAME. O canavial do século 21. 05 de fevereiro de 2009.

SICSÚ, A B.; SILVA, K. S. Desenvolvimento Rural na Zona da Mata Canavieira do Nordeste Brasileiro: Uma Visão Recente. In: Seminário: Dilema e 
Paulo Henrique de Lima Siqueira \& · 735 Luiz Gonzaga de Castro Junior

Perspectivas para o Desenvolvimento Regional com Ênfase Agrícola e Rural no Brasil na Primeira Década do Século XXI. Anais Santiago, Chile[s.n.], 11 a 13 de dez. 2001. Disponível em: <www.fao.org/regional/ Lameria/prior/>.

SHIKIDA, P. F.; BACHA, C. J. Evolução da Agroindústria Canavieira Brasileira de 1975 a 1995. In: Revista Brasileira de Economia. v. 53, n. 1, Jan./Mar. 1999, p. $69-89$

. Modernização da Agroindústria Canavieira no Brasil e as Estratégias Tecnológicas das Firmas. Revista Brasileira de Economia. v. 53, n. 1, Jan./ Mar. 1998, p. 235-254

SHEPHERD, W. G. The Economics of Industrial Organization. Waveland Press, 1999.

SINDAÇÚCAR-MG. Realidade e Perspectivas do Setor Sucroalcooleiro de Minas Com Foco no Desenvolvimento Social e Econômico. [S.I.: s.n.,] 200_.20p.

SZMRECSÁNYI T. Contribuições de Edith Penrose às teorias do progresso técnico na concorrência oligopolista. In: Revista de Economia Política. Vol. 21, n. 1 (81), janeiro-março de 2001.

VALOR ECONÔMICO - SP. Aquisições movimentam o campo em 2004. Agronegócios, B-8, São Paulo: 29/12/2004.

VEGRO, C. L. R.; FILHO, A. A. V.; AMARO, A. A. Fusões e aquisições na indústria de alimentos e bebidas: os segmentos de café, sucroalcooleiro e sucos cítricos. V Encontro de Economistas da Língua Portuguesa. Recife. 5 - 7 de novembro de 2003.

VIAN, C. E. F.; LIMA, R. A. S. Estudo de impacto econômica (EIS) para o complexo industrial canavieiro: Introdução e agenda de pesquisa. XLIII Congresso da Sociedade Brasileira de Economia, Administração e Sociologia Rural. Ribeirão Preto. Anais. Brasília: SOBER, 2005. 